\title{
The Design of Product Families for Reconfigurable Assembly Systems: Stu- dent Research Experiences
}

\section{Dr. April M. Bryan, Western Washington University}

Dr. April Bryan is an Assistant Professor at Western Washington University. Her areas of expertise are product design and development, design optimization, manufacturing systems, and concurrent engineering. She currently teaches courses in engineering drawing and graphics, manufacturing, engineering design, and mechanics.

Dr. Bryan received Ph.D. and MSc. degrees in Mechanical Engineering from the University of Michigan, Ann Arbor in 2004 and 2008 respectively. She is also a 2000 alumna of Tuskegee University, where she obtained her B.Sc. degree in Aerospace Science Engineering.

Dr. Bryan gained industrial experience as a Design Engineer at John Deere where she worked from 2000 to 2002. She has also held academic positions at Rose-Hulman Institute of Technology and the University of the West Indies, St. Augustine.

\section{Dr. John Andrew Lund, Western Washington University}

Dr. Lund's research involves the development of novel control systems, sensing and measurement tools for unique environments. His previous and ongoing research efforts include the development of a highresolution wireless instrumented mouthguard for the assessment of severity of head impacts, development of an ultra-long lifespan wireless sensor devices designed to form robust data networks in remote areas lacking infrastructure, and the development of of an electron-tunneling spectroscopy based microscope control system for molecular analysis. 


\title{
The Design of Product Families for Reconfigurable Manufacturing Systems: Undergraduate Research Experience
}

\begin{abstract}
This paper describes the experiences of a team of undergraduate research students that were assigned the task of designing a product family for a reconfigurable manufacturing system, RMS. This problem of designing a product family for a RMS required a different type of thinking than that required for traditional product design. Not only did consideration have to be given to the product design specifications and constraints, but the constraints imposed by the RMS also had to be considered. This type of thinking is not traditionally taught in existing undergraduate design curricula.

In this research experience, students adapted the traditional product design process to design a product family of lamps, with consideration of the needs of the RMS. The paper highlights the challenges posed by the systems level of thinking, and the need to include consideration of the manufacturing system. The impact of the research experience on the students and the department are discussed. Recommendations are made for approaches to conducting similar research experiences and inclusion of a systems level thinking into traditional design courses.
\end{abstract}

\section{Introduction}

Over the last thirty years, engineering programs have sought to increase the design experiences offered to their undergraduate students ${ }^{1-2}$. This increased attention to engineering design was motivated by feedback received from industry indicating that there was a need for engineering graduates who were not only technically proficient, but who were also competent at applying this knowledge to achieve realizable objectives within complex industrial environments ${ }^{1}$. In order to ensure that this objective was achieved, the Accreditation Board of Engineering and Technology ${ }^{3}$, ABET, incorporated the need for attaining proficiency in design as one of its 1-7 criteria. More specifically, the second ABET learning outcome indicates that undergraduate students should have:

an ability to apply both analysis and synthesis in the engineering design process, resulting in designs that meet desired needs

Mechanical and manufacturing engineering programs have adopted several different approaches to incorporating engineering design into their curricula. Some programs, such as the ones at Harvey Mudd, Penn State, and James Madison University, have infused engineering design throughout their curricula ${ }^{4-6}$. For these programs, students are taught basic design skills in their first year, and a scaffolding approach is used to teach them additional design skills in successive terms. Other programs, such as the ones at Michigan ${ }^{7}$, provide students with a first year engineering design experience, an intermediate design experience in either their sophomore or junior years, and a capstone design experience in their final year. Yet still, other programs concentrate all students' experiences in engineering design to final year capstone design courses, after they have completed their basic course requirements ${ }^{2}$. 
Regardless of the approach taken to incorporating engineering design into the curricula of mechanical and manufacturing engineering programs, the emphasis is typically on the teaching and learning of traditional engineering design skills ${ }^{1-7}$. For these approaches, students are provided with design targets and constraints, and are required to implement the engineering design process to realize a working prototype of a device or tool. New advanced concepts in product design are rarely taught at the undergraduate level. However, over the last twenty years, the field of engineering design has changed radically. As a result of decreased product lives and increased competition, many manufacturers no longer develop a single product for the market ${ }^{8-10}$. Instead, they simultaneously produce several products in order to ensure that they capture a significant share of the market, while maintaining efficiency and cost-effectiveness. Product family design has proven to be an effective approach in this regard. It is quickly becoming the standard approach to product development by many manufacturers of consumer and transportation products ${ }^{8-10}$.

In spite of its increased use by industrial practitioners, product family design is not part of most undergraduate engineering curricula. It is most nearly always taught at the graduate level. Some of the challenges with teaching concepts in product family design to undergraduates are: (i) The administrative effort that is required to update curricula; (ii) Lack of space in existing engineering curricula, especially since concepts in basic engineering design have to be taught first; and (iii) Faculty lack of knowledge and experience with product family design approaches. However, the teaching of concepts in product family design offers new opportunities that are not obtained through the teaching of the design of a single product. For example, in learning about product family design concepts, students have an opportunity to (i) Learn to think on a systems level; (ii) Learn to think across multiple-fields; and (iii) Learn to make trade-offs that are beneficial to a group of products. Thinking on a systems level has been a desirable skill that employers seek in undergraduate students. Given the opportunities it offers, alternative strategies to introducing and teaching product family design concepts at the undergraduate level are required.

In this research, five (5) undergraduate students learned to design product families through an undergraduate research experience. The objective of the design for the product family was to develop a product that could be built on a reconfigurable manufacturing system (RMS) ${ }^{11}$. This product family research project was a subset of a larger project that focused on the development of a RMS, which was named the Western Reconfigurable Manufacturing System, WeRMST ${ }^{12}$. This need to design the product family for the manufacturing system posed an additional challenge as manufacturing systems are typically built for product families, not the other way around. However, for this project, this was indeed the case.

This project was a beneficial learning experience for the students in many regards. Not only did the students involved in the project have to develop a design for a new product family, but they also had to learn the concepts of product family design and manufacturing system design on their own as they did so. Furthermore, in addition to having to consider the traditional product design issues such as the development of a product to meet design specifications, the students who participated in this project also had to learn to think about how the design of the product variants within the product family affected each other, as well as the design of the manufacturing system. Therefore, the learning gains of the five students who participated in this research experience 
were much more significant than they would have been from traditional product design experiences.

In addition, this undergraduate research experience provided the students with a great opportunity to develop many other skills. Through this research experience, the students learned how to work as a team, to assume responsibility for various portions of the project, to learn independently, to apply the knowledge that they learned in previous courses, to deal with uncertainty, to work with suppliers, and to document their work. These benefits are consistent with those reported by other researchers and project supervisors ${ }^{13}$.

The remainder of this paper is organized as follows. Section 2 provides a review of the literature on product family design and undergraduate research experiences. This is followed by an introduction to the product family design approach and the project organization in Sections 3 and 4 respectively. Sections 5 - 6 provide an assessment of the project and a discussion of how the lessons learned can be applied to new research experiences and engineering courses. The paper concludes with a summary in Section 7.

\section{Literature Review}

\subsection{Product Family Design}

A product family is defined as a group of products, known as product variants, that have a common base, and differentiating components that distinguish one member of the product family from the others ${ }^{8-10,14}$. Although product variants can have integrated architectures, the use of modular product architectures is typically the most efficient approach to designing product families ${ }^{15}$. With the modular design approach, differentiation of the members of the product family is obtained through scaling or swapping modules and sub-modules ${ }^{8-10,15}$. The architecture of the product family, APF, is typically used to represent the various product variants that can be obtained from a set of base modules and differentiating modules ${ }^{15-16}$.

In addition to the typical product design decisions ${ }^{17}$, there are several unique considerations that are important for the design of product families ${ }^{8-10,14}$. These include the determination of the appropriate number and mix of product variants for the product family, and the determination of modules and interfaces that could be shared across the product variants of the product family. In order to determine the former, a systems approach is usually taken to product family design. More specifically, in determining the most appropriate product line to be produced, the utility of product variants in the product family to customers, as well as the impact of product design decisions on manufacturing and the supply chain are often considered ${ }^{14,18}$. Product commonality analyses, and modular interface design are then used to elaborate the designs of modules and submodules within the product family ${ }^{16}$.

Issues of manufacturing system design are especially of concern to product family design. Traditional Dedicated Manufacturing Systems (DMS $)^{11}$, which consist of serially arranged, fixed equipment, that repeatedly produce the same components and assemblies at a high rate can be an extremely efficient approach to manufacturing. However, as the equipment in the DMS is fixed, without allowance for variation in process steps, several manufacturing systems are required to 
produce the set of product variants for a given product family. Therefore, the investment cost for this system can also be quite high. Flexible Manufacturing Systems (FMS), ${ }^{11}$ that are made of completely flexible equipment such as computer numerical machines (CNCs), are a more practical approach to producing a family of products. This approach saves on investment costs in equipment and factory space. However, the changeover time for fixtures and tooling among the different product variants of a product family can be quite high, leading to an overall inefficient manufacturing process. Reconfigurable Manufacturing Systems (RMS) ${ }^{11}$ are manufacturing systems that are specifically designed with the equipment and control infrastructure to produce a family of products. They consist of modular, adaptable, and changeable equipment that require a small amount of time to change when producing the product variants of a product family. Therefore, they can achieve near DMS efficiencies, with changeable pieces of equipment that are slightly less flexible than a FMS.

The use of a RMS places constraints on the design of a product family in terms of assembly fixtures, tooling, and process paths. The types of available tooling, and approaches to changing the tools on equipment dictate the types and sizes of features that can be used to differentiate one member of a product family from another. In addition, the various product variants have to be sized and designed so that they can be created on the same fixtures with only minor adjustments. Finally, the features on the product variants have to be positioned so as to minimize the need to reorient and reposition equipment, and machining and assembly paths when producing a set of product variants on the same manufacturing system.

In many engineering programs, topics in customer utility, concurrent engineering of products and manufacturing systems, such as the RMS, modularity, and integrability that are important to accomplishing the design of product families are often taught in graduate courses ${ }^{19}$. As a result, few undergraduates attain the skills necessary to design product families prior to graduation. As can be seen, there is value to introducing these topics earlier in engineering programs, as knowledge of these approaches have the potential to improve students' understanding of how design and manufacturing are actually accomplished by many manufacturers of consumer goods, such as those involved in the automotive, household appliance, computers, and electronic industries.

\subsection{Undergraduate Research Experiences}

Undergraduate research experiences provide numerous benefits to both students and faculty ${ }^{13,20-}$ ${ }^{22}$. In addition to giving students an opportunity to apply technical knowledge attained in classes, research experiences assist students with developing professional practice skills, such as technical communication, independent-learning, and the ability to deal with uncertainty ${ }^{13,22}$. Such experiences have been known to benefit faculties, especially at small universities. They provide faculty members with opportunities to develop research programs, increase students' motivation and retention, and serve as a recruitment tool.

The Boyer Report of $1989^{20}$ was one of the cornerstone publications supporting the use of undergraduate research as a pedagogical tool in engineering. Among the ten recommendations made by the committee, the proposal that an "inquiry-based learning" environment provides greater advantages than the traditional lecture mode of teaching has garnered the greatest 
attention. Since the publication of the report, researchers have attempted to determine whether "inquiry-based learning" environments, as manifested by undergraduate research experiences, do indeed, (i) Improve the quality of undergraduate education, (ii) Improve the quality of teaching and learning, and (iii) Improve students' undergraduate experiences ${ }^{13,22-24}$. The answers to the first and third questions have been a resounding "yes." However, there is ongoing debate as to whether undergraduate research does indeed lead to improvements in pedagogy at the undergraduate level ${ }^{13,22,25}$.

\subsection{Engineering Design and Undergraduate Research Experiences}

Although many large-scale studies have assessed the general characteristics, benefits, and drawbacks of undergraduate research experiences ${ }^{22-24}$, much less has been reported on actual undergraduate research experiences, especially in the field of engineering design. This is probably due to the fact that many believe that in order to perform research in engineering design, students should already possess the requisite design skills. However, the Boyer Report ${ }^{20}$ clearly indicated that the engineering research experience can serve as the teaching and learning tool.

Therefore, the merits of this strategy as a pedagogical tool for engineering design is still unknown. The closest related studies have been in the area of Problem Based Learning (PBL) ${ }^{26-}$

${ }^{27}$. Mills ${ }^{26}$ has noted that engineering design educators typically adopt a project based, rather than a problem based approach to teaching engineering design. This conclusion is supported by the results of studies on the effectiveness of service learning projects ${ }^{27}$, engineering design courses $^{1,28-29}$, and capstone design projects ${ }^{2,30-31}$.

However, PBL is not the same as research. This research demonstrates how engineering design can be taught to undergraduate students in an unstructured environment. In addition to basic design skills, the students who participated in this research were able to enhance their design knowledge and skills beyond those that are taught in typical undergraduate engineering design courses.

\section{Description of the Product Family Design Process}

The objective of this research experience was to design of a family of products. The design of the product family was constrained by the design of a reconfigurable manufacturing system, RMS, which was known as the WeRMST. Prior to the development of the procedure to realize the design of the product family, students devoted a considerable amount of time to learning about product family design, manufacturing systems design, RMS design, and concurrent engineering. This was done through a review of the literature on these topics.

The process for designing the product family was divided into two main phases. The first phase involved deciding on the type of product family that was to be designed within the constraints of the WeRMST ${ }^{12,14,32}$. The second phase involved the application of product family design processes to achieve the development of the selected family of products. 


\subsection{Phase 1: Determination of a Product Family to be Designed}

In deciding on the type of product family to be designed on the RMS, the team was faced with two alternatives. It could have modified the design of an existing product or it could have developed a new, clean sheet design for a product family. It is noted that the decision to adopt a new product line or to create a brand new product is one that is often faced by manufacturers in real world manufacturing environments ${ }^{18,32}$. Figure 1 shows the decision procedure that was used to determine whether to adopt or design a product family.

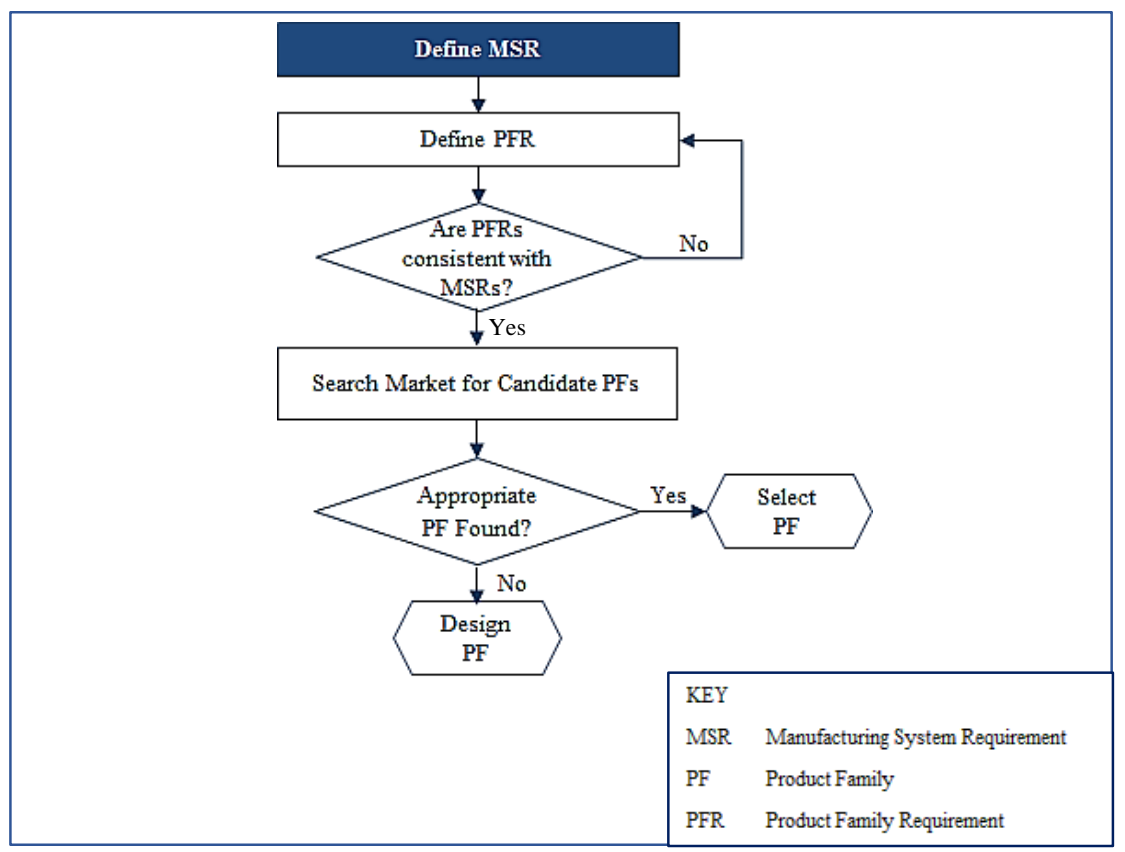

Fig. 1 Product Family Design Procedure

The first step involved the specification of the manufacturing system requirements, MSRs. The MSRs, were specified in another paper and would not be repeated here ${ }^{12}$. As shown in Fig. 1, the next step involved the determination of the product family requirements, PFRs. Table 1 shows the ten (10) PFRs that were determined to be consistent with the MSRs. One PFR specified the that the materials used to produce the product variants had to be durable and reusable. Another, required the product family to include assembly features as the WeRMST was going to include only assembly operations. This PFR further restricted the types of assembly methods to threaded fasteners, rivets and snap fits. A third PFR specified that the product variants needed to be constructed from modular components. This was done to ensure ease of assembly and to facilitate future revisions. The fourth PFR specified that the modules themselves had to be designed to be easily interchanged and updated. Since the WeRMST was required to contain a mix of automated and manual assembly operations within a laboratory setting, there was a PFR that specified that the components had to be appropriately configured and sized to be easily manipulated by robots. There was a PFR that specified the component swapping, rather than scaling product family differentiation would be used for the product family. This PFR was necessary to ensure that the developed product family would have a significant impact on the 
performance of the WeRMST. The remaining PFRs specified that the product family needed to be cost effective and aesthetically pleasing.

Following the specification of the PFRs, the next step involved the search for candidate PFs that met the PFRs. This search was performed in four (4) sub-steps. First the team identified potential product types. A total of ten different types of products were suggested. These were lamps, ladders, carts, cork-screws, multi-tools, tripods, pencils, toy cars, toy bikes, and blocks. In the next sub-step, team members voted for the four products that they believed best met the PFRs. These were found to be lamps, tripods, multi-tools, and ladders. The third sub-step involved the use of the Pugh Chart shown in Table 1 to select the most appropriate PF. Since lamps received the highest score, this product category was selected for further development. The fourth and final sub-step involved a search for a product family of lamps that met the PFRs shown in Table 1. As team members were unable to identify an existing PF of lamps that met the PFRs, and following the procedure provided in Fig. 1, a decision was made to design the PF.

Table 1 Pugh Chart for Product Type

\begin{tabular}{|c|c|c|c|c|c|c|}
\hline & CRITERIA & WEIGHTS & LAMPS & MULTI-TOOLS & TRIPODS & LADDERS \\
\hline 1 & Materials & 2 & 8 & 2 & 6 & 6 \\
\hline 2 & Assembly Operations & 4 & 8 & 2 & 4 & 8 \\
\hline 3 & Modular Design & 4 & 6 & 6 & 6 & 8 \\
\hline 4 & Changeable/Updatable & 2 & 8 & 4 & 6 & 8 \\
\hline 5 & Green & 1 & 6 & 6 & 4 & 2 \\
\hline 6 & Cost Effective & 2 & 8 & 2 & 4 & 6 \\
\hline 7 & $\begin{array}{l}\text { Components easily } \\
\text { manipulated by robots }\end{array}$ & 2 & 6 & 8 & 4 & 4 \\
\hline 8 & Aesthetically Pleasing & 1 & 8 & 6 & 6 & 4 \\
\hline 9 & Size should be appropriate & 2 & 8 & 8 & 6 & 4 \\
\hline 10 & $\begin{array}{l}\text { Type of Product Family } \\
\text { Differentiation }\end{array}$ & 2 & 6 & 6 & 4 & 4 \\
\hline & & Total & 160 & 104 & 110 & 134 \\
\hline
\end{tabular}

\subsection{Phase 2: Product Family Design Procedure}

A modified version of the traditional product family design process was used to accomplish the design of a product family ${ }^{8,14,17}$. The process consisted of the four phases as shown in Fig. 2:

(i) Preliminary Design, (ii) Conceptual Design, (iii) Detailed Design, and (iv) Design Finalization. Although the phases are drawn as distinct steps, the design process was not as linear as suggested in Fig. 2 and there was sometimes a need to make advanced decisions about successive phases or to revisit phases as the design evolved. As for the previous stages, the decisions made during each sub-phase were compared with the PFRs and MSRs, to ensure that the developed product family remained relevant to the RMS.

The Preliminary Design sub-phase for the product family was very similar to that of traditional product design ${ }^{17}$. It consisted of the definition of design objectives, development of a plan for achieving these objectives, and the definition of target design specifications and constraints, Fig. 2. As the research team was not familiar with the design of lamps, research was conducted in order to learn about the various types of lamps, their performance characteristics, and the lamp market ${ }^{33}$. This need to determine the characteristics of the lamp market such as the various segments, annual demand for each segment and consumer preferences was the main difference 
between the Preliminary Design sub-phase for the product family and that of the traditional design of a single product.

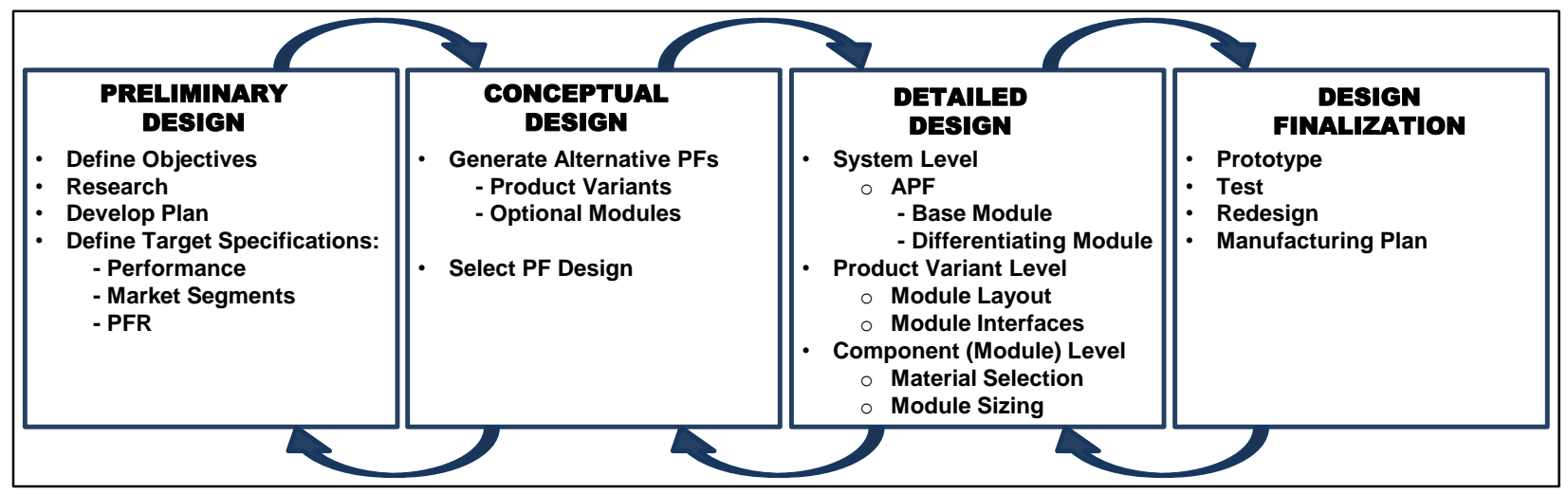

Fig. 2 Product Family Design Process

To this end, it was discovered that the lamp market was divided into two main segments, residential lamps and commercial lamps. These two segments were further subdivided into several other categories ${ }^{33}$. Of these categories, living room lamps, home office lamps, and commercial office lamps had the biggest share of the market with a total annual volume of 1.2 billion products per year. Using this knowledge, the team decided to make a pseudo market that consisted of just these three top lamps. The living room lamps, commercial office lamps, and home office lamps market segments were renamed home lamps, office lamps, and student lamps respectively. The team assumed that the distribution of products within these segments was $55 \%, 40 \%$, and $5 \%$ respectively. As a result of the well-defined market, a decision was made to develop design concepts for just these three market segments according to the known market shares, rather than to use other product family optimization processes ${ }^{8,14,18}$.

The sets of base and differentiating target design specifications shown in Table 2 were then generated. From this table it is observed that the product variants were differentiated by performance, size, cost, and aesthetics.

Table 2 Lamp Product Family Requirements

\begin{tabular}{|l|l|}
\multicolumn{1}{|c|}{$\begin{array}{c}\text { COMMON } \\
\text { REQUIREMENTS }\end{array}$} & \multicolumn{1}{|c|}{$\begin{array}{c}\text { DIFFERENTIATING } \\
\text { REQUIREMENTS }\end{array}$} \\
\hline Assembly processes & $\begin{array}{l}\text { Performance } \\
\text { Size / Weight }\end{array}$ \\
\hline Power source & Cost \\
\hline Heat generated & Aesthetics \\
\hline Type of light bulb & \\
\hline User friendliness & \\
\hline Energy Efficiency & \\
\hline Safety & \\
\hline Materials & \\
\hline
\end{tabular}


The Preliminary Design sub-phase was followed by the Conceptual Design sub-phase. This phase consisted of two steps: (i) the generation of alternatives for the product family of lamps and (ii) the selection of a suitable product family. In order to generate alternatives, a combination of brain storming, morphological charts, and analogical design techniques were used. The last two techniques were especially useful for generating unique ideas for lamps, as the team had little to no experience with the lamp product market. Although this step bears many similarities to traditional, single product design, Figs. 2 and 3 show that there were two main differences. First, there was a need to generate not just ideas for single products but for groups of product variants. Next, there was a need to generate concepts for product modules that could be used to differentiate among the product variants.

Figure 3 shows sketches of some of the product family design concepts that were generated. The traditional Pugh Decision Matrix, Table 3, was used to select the product family for the WeRMST.

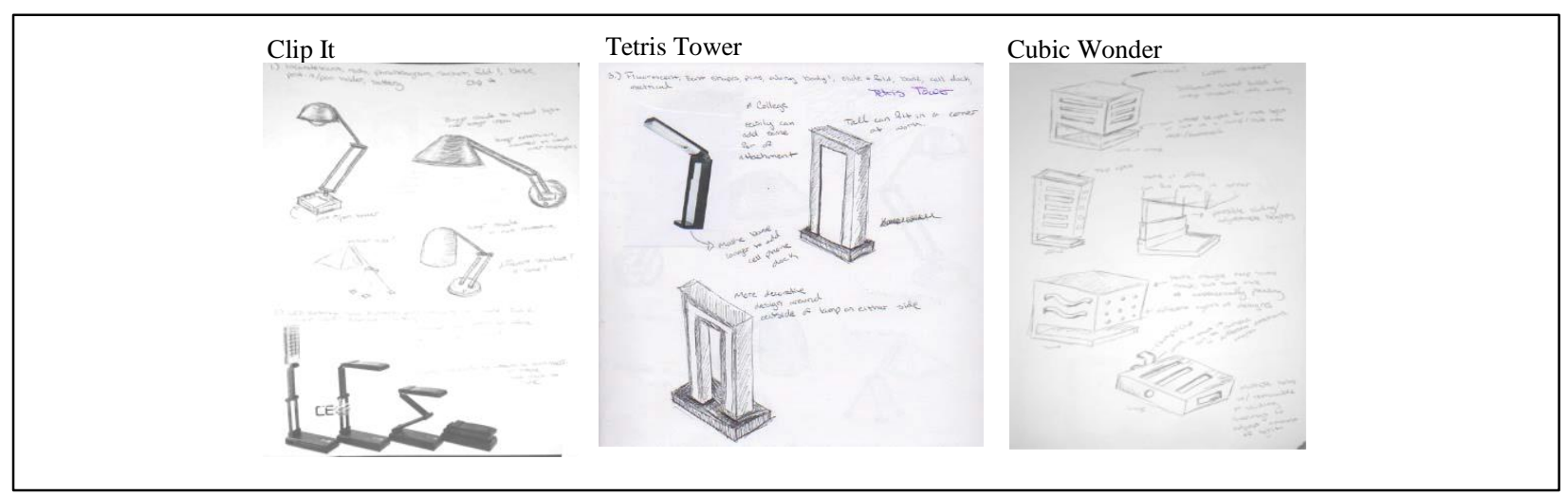

Fig. 3 Product Family Concepts

Table 3 Pugh Decision Matrix for Product Family Selection

\begin{tabular}{|l|l|r|r|}
\hline CRITERIA & WEIGHTS & $\begin{array}{c}\text { CUBIC } \\
\text { WONDER }\end{array}$ & CLIP-IT \\
\hline Manufacturing processes & 8 & 3 & 0 \\
\hline Energy Efficiency & 1 & -3 & 0 \\
\hline Safety & 4 & 1.5 & 0 \\
\hline Architecture & 8 & -1.5 & 0 \\
\hline Illumination & 4 & -3 & 3 \\
\hline Portability & 4 & 0 & 1.5 \\
\hline Durability & 2 & 3 & 0 \\
\hline Attachments & 1 & 1.5 & 3 \\
\hline Overall geometry & 8 & 0 & 1.5 \\
\hline Usability (comfort to user) & 4 & 0 & 1.5 \\
\hline Material & 4 & 3 & 1.5 \\
\hline Reconfigurability & 4 & -3 & 1.5 \\
\hline Modularity & 8 & 1.5 & 1.5 \\
\hline Cost & 2 & 1.5 & 0 \\
\hline Aesthetics & 1 & 3 & 3 \\
\hline Weighted Sum & & 28.5 & 66 \\
\hline
\end{tabular}


The Detailed Design sub-phase began with the generation of the architecture of the product family, APF, which is shown in Fig. 4. From the APF and the images of the product family provided in Fig. 5, it can be seen that the final product family consisted of twelve (12) modules, eleven (11) of which were differentiating modules. Module 1 was the only common module. Eight of the modules, Modules 2-5, 8, 9, 11, and 12, had two (2) options, while modules 6, 7, and 10 had three (3) options. The modules could have been combined in a number of different ways to generate product variants for product families of various sizes. However, following the decision made in the Preliminary Design Phase to produce only three product variants for the product family, only three (3) product variants were generated from the APF shown in Fig. 4. Therefore, the base and optional modules were combined as shown in Fig. 4 to obtain the office, home and student lamps. It is observed that the office lamp had the simplest design, while the student lamp was the most complex.

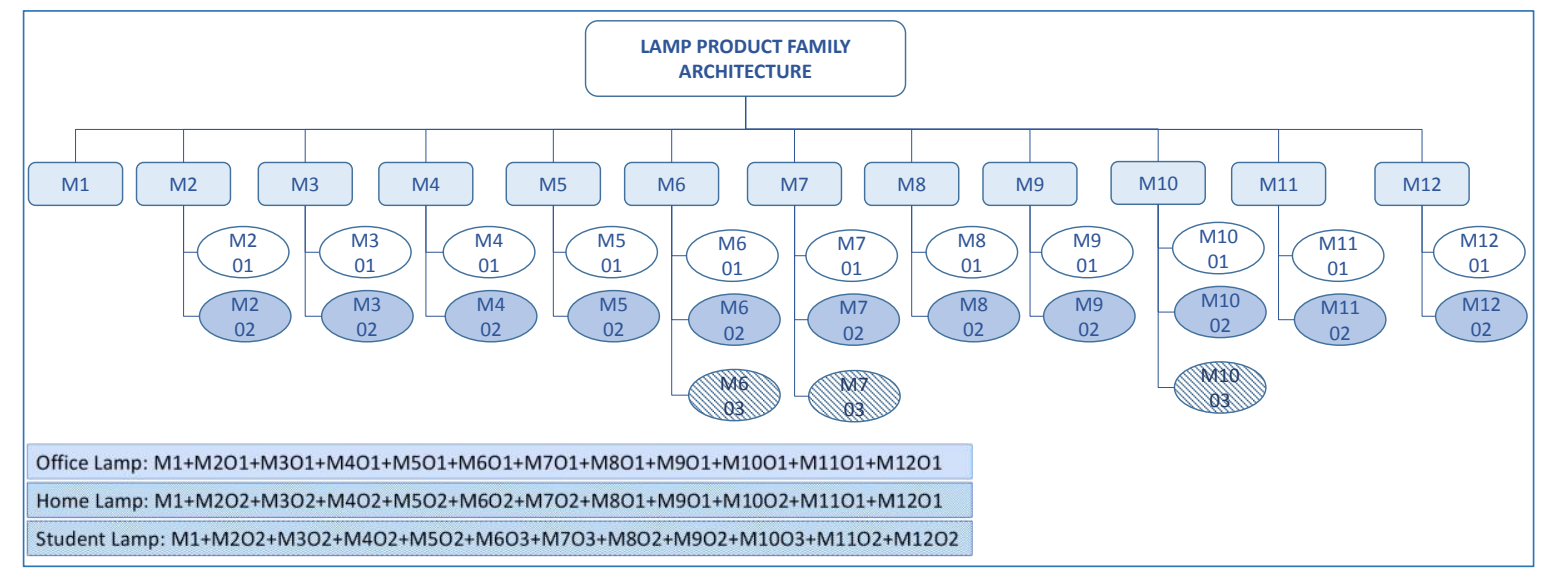

Fig. 4 Architecture of the Product Family

Other decisions made during the Detailed Design sub-phase included the sizing of the modules, selection of materials for the various modules, determination of the numbers, types and locations of fasteners, selection of the type of bulb, and the electrical connections. Reverse engineering, benchmarking, and engineering analyses were used to guide these decisions.

The configurations of the lamps shown in Fig. 5 were influenced by the selected components, intended use, and manufacturing approach. The lamps were sized to fit within an envelope of 15 $\mathrm{x} 12$ x 6 in. As a result of its light weight, strength, durability, and reusability, most of the modules were constructed from aluminum sheet metal. Nine watt (9W) compressed fluorescent light bulbs, CFL's, were selected as a result of their relatively low costs, availability, and ease of electrical connectivity. Since, each bulb required one ballast, which had a relatively large volume, extra space had to be allocated within the lamp bodies to accommodate this component. As mentioned previously, the original intent was to use a combination of fastening, riveting and spot welding operations for joining the components of the product family. However, as a result of cost and availability, a decision was made during this phase of the design process to use only fastening operations. Therefore, the designs of the modules were revised several times to ensure that they could be assembled by automated screw driving equipment. 
The detailed design of this product family and WeRMST occurred simultaneously. As a result, design decisions about the product family influenced the WeRMST and vice versa. After the product family was elaborated in CAD, a prototype of the product family was built manually with readily available materials. This prototype was assessed for feasibility of the design and ease of assembly. Due to lessons learned by this prototype build, some modules were redesigned and others were simply resized to obtain the final product family shown in Fig. 5.
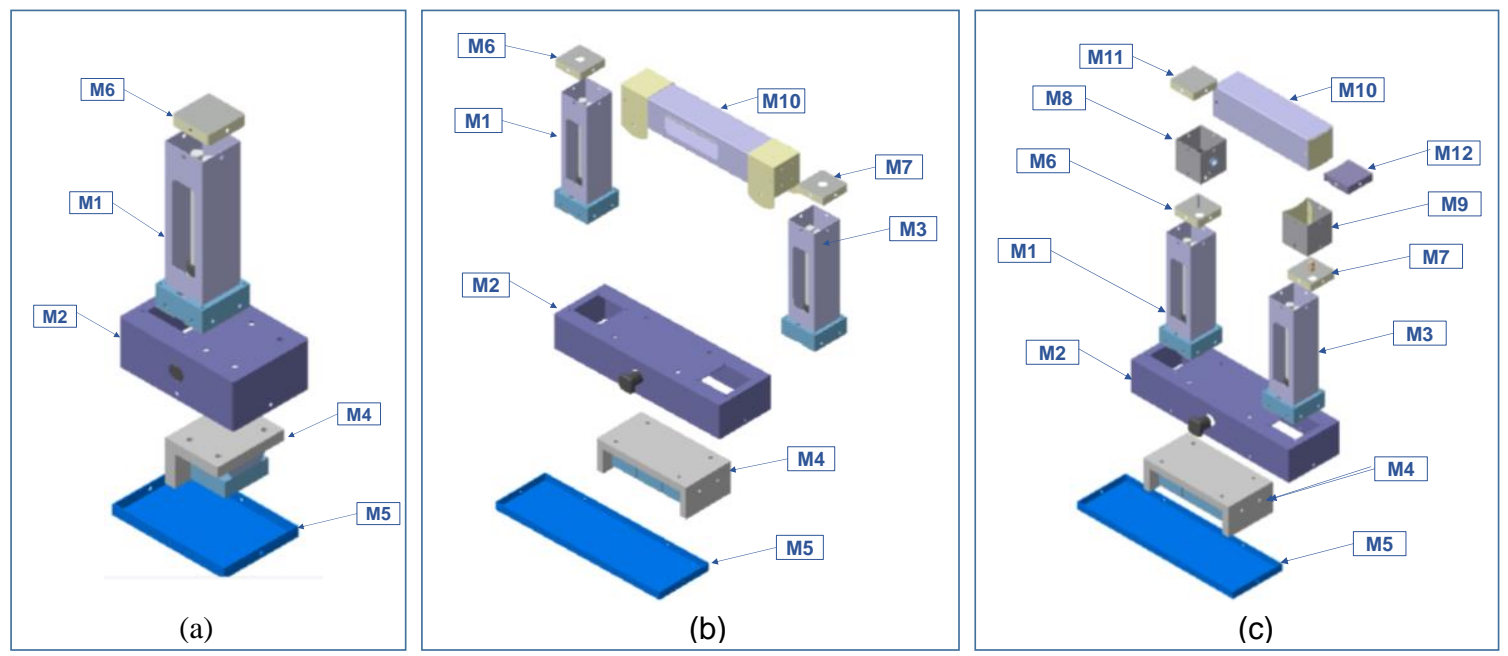

Fig. 5 Final Product Family of Lamps: (a) Office Lamp, (b) Home Lamp, (c) Student Lamp

\section{Research Team Description}

The product family was developed over a period of eight months by a team of five (5) undergraduate students. The team was not static and the size and composition of the team changed over the life of the project as shown in Table 4. The project began with one student, who completed the Preliminary Design Phase, Figs. 1-2. This student reviewed relevant literature, defined the product family design problem, developed the project plan and the product family design specifications over a period of one term. This student was then joined by two other students for the Conceptual Design Phase, which also lasted one term. The remaining two phases of the project, the Detailed Design Phase and Design Finalization Phase, were completed over one summer period by four students. Two of the four students were students who participated in the Conceptual Design Phase, and two of the students were new.

Table 4 Team Roles

\begin{tabular}{|l|c|c|c|}
\hline \multicolumn{1}{|c|}{ TASK } & QTR 1 15 & QTR 2 15 & SUMMER 15 \\
\hline Develop Specifications and Plans for the PF & Student 1 & & \\
\hline Conceptual Design of the PF & & Student 1,2,3 & \\
\hline Research on Manufacturing Processes & & Student 2 & \\
\hline Detailed Design of the PF & & & Student 2, 3, 4 \\
\hline Concurrent Design of PF \& RMS & & & Student 5 \\
\hline
\end{tabular}


The teams of students were diverse and reflective of the demographics in the department. The first student to join the project was female. This student was joined by one male and one female student for the Conceptual Design Phase. The team that completed the Detailed Design and Design Finalization Phases consisted of one female and three male students. Two of the students' were enrolled in the Plastics Engineering Program and the remaining students two students were enrolled in the Manufacturing Engineering Program.

The students assumed leadership for the aspects of the project that related to their strengths. One student, who displayed great creativity, assumed responsibility for modeling the product family. Another student, who displayed strengths in research and analysis, assumed responsibility for analyzing the performance of the product family. The student who showed strong interest in manufacturing, and who had strong shop and CAD skills, assumed responsibility for all manufacturing related issues of the product family.

During the school terms, when the Preliminary and Conceptual Design sub-phases were completed, the students' worked at home and met once a week to discuss their progress. Between meetings, they maintained communication with their supervisor and teammates via e-mail. During the summer period, when the Detailed Design and Design Finalization phases occurred, the students worked eight (8) hours per day in a lab, much like they would have in a typical internship.

\section{Impact of the Product Family Design Project}

This section provides an assessment of the impact of the product family design research experience. As this was the first implementation of this research project, it is not possible for this assessment to address high level issues such as the benefits of research experiences, the best pedagogical approaches to teaching about product families, or the benefits of teaching the systems level of thinking. Instead, this section focuses on (1) The learning experiences of the students from the viewpoint of the researchers, (2) The learning experiences of the students as reported by the students, and (3) The impact of the project on the department.

\subsection{Assessment of Student Learning: Researcher Viewpoint}

The design of the product family of lamps was successfully completed over the eight month project period. Therefore, in this regard, the project could be considered a success. However, more important than the development of a functioning product family of lamps was the fact that the project proved to be a valuable research and learning experience for the students, Table 5. There were three main learning opportunities for the students who participated in this project. As shown in Table 5, the students were provided with the opportunity to: (i) Participate in the development of a brand new design procedure, (ii) Apply knowledge and skills that they acquired from their courses, and (iii) Acquire new technical knowledge and professional skills.

All students who participated in this project had previously completed a freshman design experience, and courses in manufacturing processes. All, but one of the students, had completed a previous computer aided design, $\mathrm{CAD}$, course. In the freshman design and CAD courses, students worked on teams to design artifacts to accomplish given goals. In the manufacturing 
processes course, students were taught the characteristics and simple analyses procedures for basic manufacturing processes such as casting, machining, welding, and forming, as well as select advanced manufacturing processes, such as 3D printing and laser machining. The manufacturing processes course had an accompanying lab in which students applied their knowledge to manufacture a working device using common shop tools such as mills and lathes. Therefore, the students who had taken these courses had some prior exposure to the process of product design and development, and manufacturing processes. In addition, in these previous courses the students gained a foundation in teamwork, technical communication, and decision making, skills that were important for completing this project.

Table 5 Assessment of Student Accomplishments

\begin{tabular}{|c|c|c|}
\hline DISCOVERIES & APPLICATION & LEARNING \\
\hline \multicolumn{3}{|c|}{ TECHNICAL } \\
\hline \multirow[t]{5}{*}{ How to design PF for RMS } & Product Design Principles & RMS \\
\hline & Manufacturing Processes & Product Family \\
\hline & Computer Aided Design & Concurrent Engineering \\
\hline & Shop Skills & $\begin{array}{l}\text { Design for Forming } \\
\text { Processes }\end{array}$ \\
\hline & & Functionality of Lamps \\
\hline \multicolumn{3}{|c|}{ PERSONAL ATTRIBUTES } \\
\hline & Teamwork & Professional Responsibility \\
\hline & Technical Communication & Independent Learning \\
\hline & $\begin{array}{l}\text { Persistence / Self } \\
\text { Motivation }\end{array}$ & $\begin{array}{l}\text { Application of Scientific } \\
\text { Knowledge }\end{array}$ \\
\hline & Decision Making & Dealing with uncertainty \\
\hline & & Working with suppliers \\
\hline
\end{tabular}

\subsection{Assessment of Student Learning: Student Viewpoint}

A survey of ten questions was conducted to assess the impact of the research experience on the students. It consisted of a mix of demographic and skill assessment questions of two types : (1) Open Ended Questions, and (2) Ranking Questions. Three of the questions are provided in the Appendix. Four out of the five students who participated in the product family design project responded to the survey.

One of the open ended questions asked the participants to state three things that they learned from the research experience. The responses, with the corresponding number of responses in brackets, were as follows:

1. Engineering design process (3)

2. System design with reconfigurable manufacturing systems design in mind (2)

3. How to work with suppliers (2)

4. The difference between theoretical and actual processes (1)

5. Various unforeseen circumstances that may hinder progress (1)

6. How to better communicate with drawings and the importance of clearly presented drawings (1) 
7. Time Management (1)

8. Importance of Documentation (1)

9. Overall planning and implementation of a project (1)

Another question, provided the participants with a list of benefits of research experiences to rank order. The results are presented in Table 6. From these results, it is observed that the most beneficial experiences were identified as: (1) Learning and developing CAD skills, and (2) Learning about the challenges of implementing analytical designs. Other benefits included, understanding the research process, understanding engineering design, development of teamwork skills, and learning to work with suppliers. The students identified the learning of experimental techniques as the least beneficial learning experience. Other learning experiences that received a low rank were learning to make oral presentations, learning to analyze data, learning to use manufacturing equipment, learning to integrate theory and practice, and learning to provide evidence for assertions made.

Table 6 Assessment of Benefits of the Research Experience

\begin{tabular}{|c|c|}
\hline RESEARCH PROJECT LEARNNG EXPERIENCES & $\begin{array}{c}\text { No. of } \\
\text { Respondents }\end{array}$ \\
\hline Most Beneficial Experiences & 4 \\
\hline Learning and developing CAD skills & 3 \\
\hline Learning about the challenges of implementing analytical designs & 3 \\
\hline Understanding the research process & 2 \\
\hline Understanding engineering design & 2 \\
\hline Development of teamwork skills & 2 \\
\hline Learning to work with suppliers & 2 \\
\hline Least Beneficial Experiences & 4 \\
\hline Learning experimental techniques & 3 \\
\hline Learning to make oral presentations & 2 \\
\hline Learning to analyze data & 2 \\
\hline Learning how to use manufacturing equipment & 2 \\
\hline Learning how to integrate theory and practice & 2 \\
\hline Learning to provide evidence for assertions made & 2 \\
\hline
\end{tabular}

The survey participants were also asked to rank order a list of technical learning outcomes. The results are provided in Table 7 . These results indicate that the learning outcomes that were most reflective of the students' experiences were: (1) The design of manufacturing systems, (2) The deisgn of product families, (3) The impact of product design decisions on manufacturing systems. Other responses included the impact of product design decisions on manufacturing processes, and how to think about the designs of products and manufacturing systems concurrently. The technical learning outcomes that were least consistent with students' experiences were: (1) The design of consumer products, (2) The various types of manufacturing systems, and (3) The development of design specifications. 
Table 7 Assessment of Learning Outcomes

\begin{tabular}{|l|c|}
\hline \multicolumn{1}{|c|}{ TECHNICAL LEARNING OUTCOMES } & No. of \\
\hline \multicolumn{1}{|c|}{ Outcome Most Consistent with Experience on the Project } & 4 \\
\hline How to design manufacturing systems & 3 \\
\hline How to design product families & 3 \\
\hline How product design decisions impact manufacturing systems & 3 \\
\hline How product design decisions affect manufacturing processes & 2 \\
\hline How to think about the design or products and manufacturing systems concurrently & 2 \\
\hline \multicolumn{2}{|c|}{ Outcome Least Consistent with Experience on the Project } \\
\hline How to design consumer products & 4 \\
\hline Learning the different types of manufacturing systems & 3 \\
\hline How to develop design targets/specifications & 2 \\
\hline
\end{tabular}

\subsection{Impact on the Department}

The department of engineering and design also benefited from the successful development of the product family research experience. In addition to the obvious benefit of a co-curricular learning opportunity for students, other benefits included: (1) The development of a joint project between the Electrical Engineering and Manufacturing Engineering Programs, (2) The establishment of closer relationship with two local suppliers, and (3) The establishment of a platform for additional research experiences.

\section{Discussion and Recommendations}

\subsection{Discussion of Results}

The WeRMST research project provided the student participants with a valuable opportunity to develop new skills as described in Section 5. The results reported in Sections 5.1 and 5.2, indicate that the project was successful, not only in teaching students advanced topics in the field of engineering design, but also provided the students with an opportunity to apply that knowledge to develop new design methods and a new product family. Therefore, the project provides an example of how undergraduate students can be taught advanced topics in engineering design in an unstructured environment. The benefits of this research experience also extended beyond the immediate project. The department in which the project was conducted has already begun to realize benefits from the project.

It is believed that there were two factors that contributed to this project's success. First, completion of the project was highly dependent on the previous knowledge and experience of the students. This prior learning provided the students with a framework with which to consider the project, and assisted them with opportunities to make valuable contributions to the project from the outset. Next, as the students were required to work on the development of a tangible device and were required to interact with hardware throughout the project, their level of motivation and engagement remained high.

One drawback of this research experience was that the research question was very well defined and the students were mainly responsible for fulfilling the objective. The advantages of this 
approach was that it shortened the length of time that was required for students to fully engage in the project and to realize results. The clearly defined path was probably another contributing factor to the high level of motivation at the start of the project. However, this approach resulted in a missed learning opportunity, as a valuable part of a research experience is the ability to define the research problem, and to scope the work $^{13,22-23}$.

A surprising result was that students ranked the integration of theory as one of the least beneficial research experiences. However, learning about the challenges of implementing analytical designs was ranked as one of the highest. These results are in conflict with each other. The latter response indicates that the students did learn about the integration of theory and practice. However, the former response shows that the students lacked the appropriate language to explain it.

\subsection{Recommendations for Future Courses}

The benefits of the project may also contribute to the enhancement of undergraduate product design courses. While product family design is an important approach used in consumer good industries, it is often taught only at the graduate level. The teaching of this topic at the graduate level is often approached mathematically with a focus on topics such as the optimization of the design of the product family, or the development of algorithms for product variant selection and product family sizing.

However, this project provides an example of how the subject of product family design can be taught at the undergraduate level. Some topics in product family design that can be included in an undergraduate level course include:

1. Types of Product Architectures

Integrated vs. Modular Architectures

\section{Product Family Representation}

Representations that are applicable to the design of manufacturing systems. These include:

2.1. The architecture of the product family (Fig. 3)

2.2. Liaison diagrams

2.3. Precedence Diagrams

3. Product Variant Differentiation

3.1. Approaches to product differentiation:

Module scaling vs module swapping

3.2. Impact of product variant differentiation on the remainder of the product development process

4. Product Family Design Considerations

4.1. Design of a common base

4.2. Design of Modular Interfaces

4.3. Mix and number of product variants to include in the product family 


\section{Conclusion}

In this research, a team of five (5) undergraduate students developed the design of a product family within the constraints of a RMS. As the problem was to design a product family to meet the needs of a manufacturing system, rather than the conventional design problem of designing a product and then a manufacturing system, the students had to learn to think on the systems level and to develop new approaches to product family design. In this project, the students used existing and new approaches to product family design to successfully design a product family of lamps.

Although the students involved in the project had prior knowledge and skills in product design and manufacturing processes, they were unfamiliar with product family design and RMSs. These latter two subjects they learned as they implemented the project. In addition to the opportunity to extend their technical knowledge base, the project provided students with opportunities to develop professional skills such as life-long learning, research methods, communicating with suppliers and documentation. In these regards, the benefits of this research were consistent with prior studies that indicated that experiences such as these can be valuable teaching and learning tools.

Two attributes of this project that can be used when creating future undergraduate research projects are (i) To ensure that students have a good deal of familiarity with the subject, and (ii) To ensure that the project has a tangible component. These attributes were found to be useful for motivating students and maintaining their interest throughout the project. The one aspect of this research that could have been improved was the creation of opportunities for students to define the research question and scope of work.

The benefits of this research can potentially extend beyond this project to future research projects, and courses in engineering design. Topics that can be included an undergraduate course in product family design were proposed in the paper.

\section{REFERENCES}

[1] Dym, C. L., Agogino, A. M., Eris, O., Frey, D. D., \& Leifer, L. J. (2005). Engineering design thinking, teaching, and learning. Journal of Engineering Education, 94(1), 103-120.

[2] Howe, S. (2010). Where are we now? Statistics on capstone courses nationwide. Advances in Engineering Education, 2(1), 1-27.

[3] Accreditation Board of Engineering and Technology. (2016-2017). Criteria for evaluating engineering programs. ABET. Baltimore, MD, USA.

[4] Dym, C. L. (2004). Design, systems, and engineering education. International Journal of Engineering Education, 20(3), 305-312. 
[5] Lamancusa, J. S., Jorgensen, J. E., \& Zayas-Castro, J. L. (1997). The learning factory-A new approach to integrating design and manufacturing into the engineering curriculum. Journal of Engineering Education, 86(2), $103-112$.

[6] Pierrakos, O., Nagel, R. L., Pappas, E., \& Nagel, J. K. (2012). A new vision for engineering design instruction: On the innovative six course design sequence of James Madison University. In 119th ASEE Annual Conference \& Exposition, San Antonio, TX, USA, 9-13 June.

[7] Dutta, D., Geister, D. E., \& Tryggvason, G. (2004). Introducing hands-on experiences in design and manufacturing education. International Journal of Engineering Education, 20(5), 754-763.

[8] Martin, M. V., \& Ishii, K. (2002). Design for variety: developing standardized and modularized product platform architectures. Research in Engineering Design, 13(4), 213-235.

[9] Fellini, R., Kokkolaras, M., Papalambros, P., \& Perez-Duarte, A. (2005). Platform selection under performance bounds in optimal design of product families. Journal of Mechanical Design, 127(4), 524-535.

[10] Jiao, J. R., Simpson, T. W., \& Siddique, Z. (2007). Product family design and platform-based product development: a state-of-the-art review. Journal of intelligent Manufacturing, 18(1), 5-29.

[11] Koren, Y., Heisel, U., Jovane, F., Moriwaki, T., Pritschow, G., Ulsoy, G., \& Van Brussel, H. (1999). Reconfigurable manufacturing systems. CIRP Annals-Manufacturing Technology, 48(2), 527-540.

[12] Bryan, A., and Lund, J. (2016). The design of a reconfigurable manufacturing system testbed for teaching courses in manufacturing system design. In $122^{\text {nd }}$ ASEE Annual Conference \& Exposition, New Orleans, LA, USA, 26-29 June.

[13] Lopatto, D. (2003). The essential features of undergraduate research. Council on Undergraduate Research Quarterly, 24, 139-142.

[14] Bryan, A., Wang, H., \& Abell, J. (2013). Concurrent Design of Product Families and Reconfigurable Assembly Systems. Journal of Mechanical Design, 135(5), 051001.

[15] Ulrich, K. (1995). The role of product architecture in the manufacturing firm. Research Policy, 24(3), 419-440.

[16] Tseng, M. M., \& Jiao, J. (1998). Design for mass customization by developing product family architecture. In Design Engineering Technical Conferences-Design Theory and Methodology, Atlanta, GA, USA, 13-16 September.

[17] Eppinger, S. D., \& Ulrich, K. T. (1995). Product design and development. Mc Graw Hill, NY, USA.

[18] Li, H., \& Azarm, S. (2002). An approach for product line design selection under uncertainty and competition. Journal of Mechanical Design, 124(3), 385-392.

[19] Simpson, T. W., \& Thevenot, H. J. (2005). Using product dissection to integrate product family design research into the classroom and improve students' understanding of platform commonality. In ASME 2005 International Design Engineering Technical Conferences and Computers and Information in Engineering Conference, Long Beach, CA, USA, 24-28 September.

[20] Kenny, R. W., Alberts, B., Booth, W. C., Glaser, M., Glassick, C. E., Ikenberry, S. O., \& Jamieson, K. H. (1998). Reinventing undergraduate education: A blueprint for America's research universities. Boyer Commission on Educating Undergraduates in the Research University.

[21] Attarzadeh, F., Fitzgibbon, W., Barbieri, E., \& Ramos, M. (2009). Situating a senior project course in a university QEP research-based institutional framework. Engineering Technology Opens the Door to a World of Opportunity, 1(2), 51-56. 
[22] Katkin, W. (2003). The Boyer Commission Report and its impact on undergraduate research. New Directions for Teaching and Learning, 93, 19-38.

[23] Hu, S., Kuh, G. D., \& Gayles, J. G. (2007). Engaging undergraduate students in research activities: Are research universities doing a better job? Innovative Higher Education, 32(3), 167-177.

[24] May, G. S., \& Chubin, D. E. (2003). A retrospective on undergraduate engineering success for underrepresented minority students. Journal of Engineering Education, 92(1), 27-39.

[25] Prince, M. J., Felder, R. M., \& Brent, R. (2007). Does faculty research improve undergraduate teaching? An analysis of existing and potential synergies. Journal of Engineering Education, 96(4), 283-294.

[26] Mills, J. E., \& Treagust, D. F. (2003). Engineering education-Is problem-based or project-based learning the answer? Australasian Journal of Engineering Education, 3(2), 2-16.

[27] Neill-Carrillo, E. O., Martínez-Navedo, T., Ramos, J., Vélez-Reyes, M., \& Marrero, E. (2002). Undergraduate research and new laboratory practices in power engineering. In 32nd Annual Frontiers in Education, Boston, MA, USA, NY, USA, 6-9 November.

[28] Bailey, R., \& Szabo, Z. (2007). Assessing engineering design process knowledge. International Journal of Engineering Education, 22(3), 508.

[29] Chulvi, V., Sonseca, Á., Mulet, E., \& Chakrabarti, A. (2012). Assessment of the relationships among design methods, design activities, and creativity.Journal of Mechanical Design, 134(11), 111004.

[30] Dutson, A. J., Todd, R. H., Magleby, S. P., \& Sorensen, C. D. (1997). A Review of Literature on Teaching Engineering Design Through Project-Oriented Capstone Courses. Journal of Engineering Education, 86(1), 17-28.

[31] Sobek, D. K., \& Jain, V. K. (2004). Two instruments for assessing design outcomes of capstone projects. In Proceedings of the American Society of Engineering Education Conference, Salt Lake City, Utah, USA, 20-23 June.

[32] Bryan, A., Ko, J., Hu, S. J., \& Koren, Y. (2007). Co-evolution of product families and assembly systems. CIRP Annals-Manufacturing Technology, 56(1), 41-44.

[33] Ashe, M., de Monasterio, M. C., Gupta, M., \& Pegors, M. (2012). 2010 US Lighting Market Characterization. Report to US Department of Energy. 


\section{APPENDIX}

\section{Select questions from the WeRMST Project Survey}

1. List three (3) things you learned from this research experience.

2. The following is a list of potential Benefits of research experiences. Please review the list and rank the five items that you felt were the most beneficial learning experiences and the five items that were the least beneficial learning experiences in descending order. In order to rank the items, you need to drag the items from the left column into the appropriate box on the right. For example, for the Most Beneficial Group, Item 1 will be most beneficial, "best", learning experience, and Item 5 will be the fifth most beneficial learning experience. For the Least Beneficial Group, Item 1 will be the least beneficial, "worst", learning experience, and Item 5 will be the fifth least beneficial item.

\begin{tabular}{|c|c|}
\hline Most Beneficial Learning Experiences & Least Beneficial Learning Experiences \\
\hline 1. Understanding the research process & Understanding the research process \\
\hline Readiness for more demanding research & Readiness for more demanding research \\
\hline Understanding how engineers work on real problems & 3. Understanding how engineers work on real problems \\
\hline Learning experimental techniques & 4. Learning experimental techniques \\
\hline Learning how to use manufacturing equipment & 5. Learning how to use manufacturing equipment \\
\hline Learning to formulate a research question & 6. Learning to formulate a research question \\
\hline $\begin{array}{l}\text { 7. Learning about the challenges of implementing analytical } \\
\text { designs }\end{array}$ & $\begin{array}{l}\text { 7. Learning about the challenges of implementing } \\
\text { analytical designs }\end{array}$ \\
\hline 8. Learning to tolerate obstacles & 8. Learning to tolerate obstacles \\
\hline 9. Development of decision making skills & 9. Development of decision making skills \\
\hline 10. Learning how to work independently & 10. Learning how to work independently \\
\hline 11. Learning to interpret results & 11. Learning to interpret results \\
\hline $\begin{array}{l}\text { 12. Development of a plan to address or resolve engineering } \\
\text { problems }\end{array}$ & $\begin{array}{l}\text { 12. Development of a plan to address or resolve engineering } \\
\text { problems }\end{array}$ \\
\hline 13. Learning how to perform engineering analysis & 13. Learning how to perform engineering analysis \\
\hline 14. Learning and developing CAD skills & 14. Learning and developing CAD skills \\
\hline 15. Learning to analyze data & 15. Learning to analyze data \\
\hline 16. Understanding how knowledge is constructed & 16. Understanding how knowledge is constructed \\
\hline 17. Learning to work with suppliers & 17. Learning to work with suppliers \\
\hline 18. Development of teamwork skills & 18. Development of teamwork skills \\
\hline 19. How to form supportive networks & 19. How to form supportive networks \\
\hline 20. Learning how to integrate theory and practice & 20. Learning how to integrate theory and practice \\
\hline 21. Understanding primary literature & 21. Understanding primary literature \\
\hline 22. Learning to provide evidence for assertions made & 22. Learning to provide evidence for assertions made \\
\hline 23. Understanding engineering design & 23. Understanding engineering design \\
\hline 24. Understanding how technicians think & 24. Understanding how technicians think \\
\hline 25. Self-confidence & 25. Self-confidence \\
\hline 26. Clarification of a career path & 26. Clarification of a career path \\
\hline 27. Learning to make oral presentations & 27. Learning to make oral presentations \\
\hline 28. Learning to write scientific articles & 28. Learning to write scientific articles \\
\hline Learning ethical conduct & 29. Learning ethical conduct \\
\hline Development of leadership skills & 30. Development of leadership skills \\
\hline
\end{tabular}

3. The following is a list of potential Technical Learning Outcomes of research experiences in engineering. Please review the list and rank the five Technical Learning Outcomes that are most representative of your research experience and the five Technical Learning Outcomes that are least representative of your research experience in descending order. In order to rank the items, you need to drag the items from the left column into the appropriate box on the right. For example, for the Best Learning Outcomes Group, Item 1 will be the Learning Outcome that is most consistent with your experience, and Item 5 will be the fifth most consistent learning 
outcome. For the Least Beneficial Group, Item 1 will be the Learning Outcome that is least consistent with your experience and Item 5 will be the fifth least consistent learning outcome.

Learning Outocmes that Best Represent Your Experience

1. How to design manufacturing systems

2. How to design consumer products

3. How to design product families

4. Learning the different types of product families

5. Learning the different types of manufacturing systems

6. Learning about different types of manufacturing

7. How product design decisions impact manufacturing systems

8. How product design decisions affect manufacturing processes

9. How to think about the design or products and manufacturing systems concurrently

10. The entire process of product development

11. The entire process of manufacturing system

12. The combined process of product development and manufacturing system development

13. The entire process of manufacturing system development

14. How to perform analyses to ensure product design performance

15. How to perform analyses to ensure manufacturing system performance

16. How to perform analyses to ensure that both product design and manufacturing system performance are achieved

17. How to develop design targets/specifications

18. How to generate design alternatives

19. How to select from among a set of design alternatives

20. How to make various types of design decisions to accomplish a given set of constraints

21. How availability of equipment can affect design decisions

22. The impact of lead times and cost on design decisions

23. How to work with others, suppliers and technicians, to accomplish realistic designs

24. Organizational skills

25. Computer Aided Design (CAD) Skills
Learning Outcomes that Least Represent Your Experience

1. How to design manufacturing systems

2. How to design consumer products

3. How to design product families

4. Learning the different types of product families

5. Learning the different types of manufacturing systems

6. Learning about different types of manufacturing

7. How product design decisions impact manufacturing systems

8. How product design decisions affect manufacturing processes

9. How to think about the design or products and manufacturing systems concurrently

10. The entire process of product development

11. The entire process of manufacturing system

12. The combined process of product development and manufacturing system development

13. The entire process of manufacturing system development

14. How to perform analyses to ensure product design performance

15. How to perform analyses to ensure manufacturing system performance

16. How to perform analyses to ensure that both product design and manufacturing system performance are achieved

17. How to develop design targets/specifications

18. How to generate design alternatives

19. How to select from among a set of design alternatives

20. How to make various types of design decisions to accomplish a given set of constraints

21. How availability of equipment can affect design decisions

22. The impact of lead times and cost on design decisions

23. How to work with others, suppliers and technicians, to accomplish realistic designs

24. Organizational skills

25. Computer Aided Design (CAD) Skills 